\title{
ADUBAÇÃO FOSFATADA E POTÁSSICA NA FORMAÇÃO DE MUDAS DE TAMARINDEIRO
}

\section{PHOSPHATE AND POTASSIC FERTILIZATION ON SEEDLING PRODUCTION OF TAMARIND FRUIT}

\author{
Ester Alice FERREIRA ${ }^{1}$ \\ Vander MENDONÇA ${ }^{2}$ \\ Henrique Antunes de SOUZA ${ }^{3}$ \\ José Darlan RAMOS ${ }^{4}$
}

\begin{abstract}
RESUMO
O conhecimento do manejo da adubação na propagação de frutíferas é fundamental para obtenção de mudas bem formadas que garantirão o sucesso na implantação e, conseqüentemente, na produtividade de pomares. No caso do tamarindeiro, ainda são poucas as pesquisas nessa área, o que levou a execução deste trabalho, que teve como objetivo avaliar os efeitos da adubação potássica e fosfatada no desenvolvimento de mudas de tamarindeiro. $O$ experimento foi conduzido em casa de vegetação com $50 \%$ de luminosidade, com delineamento experimental blocos casualizados num esquema fatorial $4 \times 4$, sendo testadas quatro doses de fósforo tendo como fonte o superfosfato simples a $0 ; 2,5 ; 5,0$ e 10,0 $\mathrm{kg} \mathrm{m}^{-3}$ e quatro de potássio tendo como fonte o cloreto de potássio a $0 ; 1 ; 2 ;$ e $4 \mathrm{~kg} \mathrm{~m}^{-3}$ de substrato. Cento e vinte dias após a germinação procedeu-se a avaliação das seguintes características: altura de mudas e comprimento de raiz, número de folhas, peso da massa seca de raiz e parte aérea. Recomenda-se a aplicação de $3 \mathrm{~kg} \mathrm{~m}^{-3}$ de cloreto de potássio para maior altura das mudas e $5 \mathrm{~kg} \mathrm{~m}^{-3}$ de superfosfato simples para ganhos em comprimento de raiz e número de folhas.
\end{abstract}

Palavras-chaves: Tamarindus Indica; propagação; nutrição mineral

\begin{abstract}
The knowledge of the fertilization practices on fruit propagation is important in order to obtain well formatted seedlings which will warranty the success on implementation and high productivity of the orchards. However the researches with this species it is quite a few yet, especially on seedling production. The present work aimed to evaluated the effects of potassic and phosphate fertilization on seedling development of tamarind fruit Tamarindus indica, $\mathrm{L}$. The experiment was carried out in $50 \%$ luminosity greenhouse, and the experimental design adopted was randomized block in a factorial scheme $4 \times 4$ : 4 doses of $\mathrm{P} 0,150,300$ e $600 \mathrm{~kg} \mathrm{~m}^{-3}$ of simple super phosphate and 4 doses of $\mathrm{K} 0,75,150 \mathrm{e} 300 \mathrm{~kg} \cdot \mathrm{m}^{-3}$ of KCl. One hundred and twenty days after germination the seedling were evaluated by the following characteristics: length of aerial and root part, number of leaves, dry weight mass of root and aerial part. It is recommended the application of potassium chloride at $3 \mathrm{~kg} \mathrm{~m}^{-3}$ to increase aerial part and single super phosphate at $5 \mathrm{~kg} \mathrm{~m}^{-3}$ for root length and number of leaves.
\end{abstract}

Key-words: Tamarindus Indica L; propagation; mineral nutrition

\footnotetext{
${ }^{1}$ Eng. Agr. Dra. Pesquisadora da EPAMIG C.P 35138060040 Uberaba MG E-mail: ester@epamig.br;

${ }^{2}$ Eng. Agr. Dr. Prof. Adjunto UFERSA BR 110 - km 47 Bairro Pres. Costa e Silva CEP 59625-900 Mossoró - RN - E-mail: vander@ufersa.edu.br

${ }^{3}$ Eng. Agr. Mestrando Produção Vegetal, UNESP, Jaboticabal/SP. E-mail: henrique.antuness@yahoo.com.br

${ }^{4}$ Eng. Agr. Dr. Prof. Adjunto,UFLA. CP 303737200000 Lavras MG E-mail: darlan@ufla.br
} 


\section{INTRODUÇÃO}

O tamarindeiro Tamarindus indica L., tem seu centro de origem nas Índias, mas já há um século vem sendo cultivado no Brasil, principalmente nos Estados da região nordeste, sendo considerado uma árvore de multiuso. Dele aproveitam-se a madeira, as sementes, as folhas para forragem animal, para obtenção de extratos medicinais e componentes industriais e condimentares. Mas é na fruticultura que essa espécie vem se destacando. Sua polpa tem sido amplamente usada no preparo de doces, bolos, sorvetes, xaropes, licores, refrescos e principalmente sucos concentrados.

As plantas dessa espécie levam aproximadamente 280 dias após a antese para completar o ciclo desde a floração até a colheita e a maturação fisiológica dos frutos, coincide com o desprendimento natural da planta-mãe e a maturação das sementes (GURJÂO et al., 2006).

A propagação do tamarindeiro é predominantemente sexuada e ainda são poucas informações sobre a formação de mudas dessa espécie, que tem sido realizada de forma empírica. Os estudos já realizados por MARTINS et al. (2002) mostraram que quando se almeja quantidade e velocidade de resposta, quanto à germinação de sementes, a semeadura deve ser realizada tão logo as sementes forem retiradas dos frutos. Já MENDONÇA et al. (2008) avaliaram os efeitos do Osmocote $^{\circledR}(15-10-10)$ na formação de mudas de tamarindeiro onde a dose $6,0 \mathrm{~kg} \mathrm{~m}^{-3}$ promoveu os melhores resultados. O mesmo estudo revelou que adubo testado não teve efeito sobre desenvolvimento das raízes, mostrando a necessidade de mais pesquisas com outros adubos na formação de mudas para assegurar o sucesso na expansão dessa espécie em novos plantios

Sobre a participação dos nutrientes no desenvolvimento vegetal, MALAVOLTA et al. (1997) citado por ORLANDO et al. (2004) destacam a importância do fósforo, por estar presente na constituição de moléculas essenciais para as plantas: DNA (ácido desoxirribonucléico), o RNA (ácidos ribonucléicos), polímeros de nucleotídios, ésteres e Pi (fósforo inorgânico). Na germinação, os mesmos autores ressaltam que em quantidades adequadas, o fósfoto estimula o desenvolvimento radicular, é essencial para a boa formação da planta e incrementa a produção. O uso do superfosfato simples tem sido amplamente usado como fornecedor de fósforo às plantas, pois contem na sua composição química cálcio $(25-28 \% \mathrm{CaO})$ e enxofre (12\%) (CARMELLO, 1995).

O potássio desempenha funções essenciais na translocação de açúcares, na formação de amido, no aumento da resistência da planta à seca, no controle do mecanismo de abertura e fechamento dos estômatos, sendo, também, ativador de inúmeras enzimas de capital importância no metabolismo das plantas (ANDA, 2001)

Entretanto a utilização do potássio na semeadura requer cuidados, pois este pode afetar significativamente a germinação da semente e até a arquitetura da raiz em decorrência de possíveis efeitos salinos do $\mathrm{KCl}$. Em regiões áridas ou sujeitas a déficit hídrico esse efeito é mais provável, pois há maior concentração de sais na solução do solo que podem danificar as sementes ou raízes (KLUTHCOUSKI e STONE, 2003)

$\mathrm{Na}$ formação de mudas, as adubações potássica e fosfatada têm proporcionado bom desenvolvimento de raízes e plântulas, favorecendo a resistência a diversas doenças (INSTITUTO DA POTASSA \& FOSFATO, 1998). A interação positiva entre fósforo e potássio tem sido relatada em diversas espécies frutíferas como maracujazeiro (ALMEIDA, 2006); bananeira (SOUSA et al., 1999) e gravioleira (SOUZA et al., 2003 MENDONÇA et al., 2007); mostrando que a resposta das culturas à adubação pode ser mais dependente da interação entre nutrientes do que do nutriente isolado e evidenciando a importância da realização de ensaios de adubação fatoriais que contribuem para a prática para o manejo racional da adubação.

Diante da escassez de informações para formação de mudas do tamarindeiro, o presente trabalho objetivou avaliar os efeitos do Fósforo e Potássio nesta fase, via adubação com superfosfato simples e cloreto de potássio no substrato.

\section{MATERIAL E MÉTODOS}

O experimento foi conduzido em um viveiro de formação de mudas frutíferas da Universidade Federal de Lavras (UFLA), MG, cercado com telado de nylon tipo sombrite, permitindo $50 \%$ de luminosidade no seu interior e uma boa ventilação. Foi instalado no mês de abril de 2004 que teve como temperatura média $21^{\circ} \mathrm{C}$.

As sementes usadas foram provenientes do pomar didático do campus da Escola Agrotécnica Federal de Souza-PB e foram semeadas em sacos plásticos $(10 \times 20 \mathrm{~cm})$ furados lateralmente, com capacidade para $500 \mathrm{~mL}$ de substrato. Foram utilizadas 2 sementes por recipiente e, após a germinação, quando as mudas atingiram $5 \mathrm{~cm}$ foram desbastadas deixando-se a mais vigorosa.

Como substrato utilizou-se uma mistura com os componentes: composto orgânico + areia + solo na proporção de 1:2:3 em volume, com a seguinte composição química: $\mathrm{pH}=6,0 ; \mathrm{P}=15,0 \mathrm{mg}$ $\mathrm{dm}^{-3} ; \mathrm{K}=72 \mathrm{mg} \mathrm{dm}^{-3} ; \mathrm{Ca}=4,0 \mathrm{cmol}^{-3} ; \mathrm{Mg}=1,4 \mathrm{cmol}^{-3}$ $\mathrm{dm}^{-3} ; \mathrm{Zn}=3,4 \mathrm{mg} \mathrm{dm}{ }^{-3} ; \mathrm{Fe}=49,6 \mathrm{mg} \mathrm{dm}^{-3} ; \mathrm{Mn}=20,7$ $\mathrm{mg} \mathrm{dm}^{-3} ; \mathrm{Cu}=2,0 \mathrm{mg} \mathrm{dm}^{-3} ; \mathrm{B}=1,0 \mathrm{mg} \mathrm{dm}^{-3} ; \mathrm{S}=13,8$ $\mathrm{mg} \mathrm{dm}$; soma de bases $S B=5,6 \mathrm{cmol}^{-3} \mathrm{dm}^{-3}$; Capacidade de troca de cátions a $\mathrm{pH} 7^{\mathrm{C}} \mathrm{T}=7,5$ $\mathrm{cmol}_{\mathrm{c}} \mathrm{dm}^{-3}$; saturação por bases do solo $\mathrm{V}=74,6 \%$ e matéria orgânica $=1,6$ dag kg $^{-1}$. O pH foi determinado em água, $\mathrm{KCl}$ e $\mathrm{CaCl}_{2}$ - relação 1:2,5. O P, K, Fe, Zn, $\mathrm{Mn}$ e Cu foram determinados por extrator de Mehlich 1. $\mathrm{O} \mathrm{Ca} \mathrm{e} \mathrm{o} \mathrm{Mg}$ foram determinados por extrator $\mathrm{KCl}$ $1 \mathrm{~N}$. O B foi determinado por extrator água quente e o $S$ por extrator fosfato monocálcico em ácido acético. 
A matéria orgânica foi determinada por oxidação: $\mathrm{Na}_{2} \mathrm{Cr}_{2} \mathrm{O}_{7} 4 \mathrm{~N}+\mathrm{H}_{2} \mathrm{SO}_{4} 10 \mathrm{~N}$.

$\mathrm{O}$ delineamento experimental utilizado foi o de blocos casualizados, em esquema fatorial $4 \times 4$, com quatro repetições e cinco plantas por parcela. Utilizaram-se quatro doses de super fosfato simples $\left(0 ; 2,5 ; 5,0\right.$ e $10,0 \mathrm{~kg} \mathrm{~m}^{-3}$ de substrato) e quatro doses de cloreto de potássio $\left(0 ; 1 ; 2\right.$; e $4 \mathrm{~kg} \mathrm{~m}^{-3}$ de substrato). Os adubos foram misturados ao substrato na época de enchimento dos sacos plásticos para produção das mudas.

Pela irrigação buscou-se a umidade do substrato. Esta foi realizada com regador manual no início da manhã e final da tarde até a avaliação das mudas. Foram realizadas ainda inspeções semanais para controle de pragas doenças e uma vez que não foi encontrado nenhum sintoma, não foi aplicado controle para este fim. Nas mesmas inspeções foram identificadas plantas daninhas que foram arrancadas manualmente.

Após 120 dias da semeadura avaliaramse as seguintes características: altura de mudas $(\mathrm{cm})$, comprimento de raiz $(\mathrm{cm})$, número de folhas.
As partes foram colocadas em estufa à temperatura de $65^{\circ} \mathrm{C}$, até atingir peso constante e, em seguida, pesadas, encontrando-se a matéria seca da parte aérea e matéria seca da raiz.

As análises foram realizadas pelo programa SISVAR (FERREIRA, 2000), onde os dados foram submetidos à análise de variância e quando constatada a significância foi realizada a regressão polinomial (GOMES, 2000).

\section{RESULTADOS E DISCUSSÃO}

Os efeitos significativos detectados pelo teste $F$ para a interação das doses de cloreto de potássio e do superfosfato simples foram registrados apenas para altura das mudas. Para as variáveis: comprimento de raiz e número de folhas houve efeito significativo apenas para os adubos testados isoladamente e não houve efeito estatístico dos tratamentos nas demais variáveis analisadas (Tabela 1).

TABELA 1 - Resumo da análise de variância (Quadrado Médio) para altura de mudas (AM), comprimento de raiz (CR), número de folhas (NF), peso da matéria seca da parte aérea e da raiz (PMSPA e PMSR) em função das doses de cloreto de potássio $(\mathrm{KCl})$ e do superfosfato simples no crescimento de mudas de tamarindeiro.

\begin{tabular}{lcccccc}
\hline FV & GL & AM & CR & NF & PMSPA & PMSR \\
\hline $\mathrm{KCl}$ & 3 & 96,1872 & $125,8028^{* *}$ & 0,1712 & 12,1686 & 25,5664 \\
SSimples & 3 & 107,1696 & $78,8593^{*}$ & $8,3522^{*}$ & 56,3383 & 32,2764 \\
$\mathrm{KCl} x$ & 9 & $139,4940^{* *}$ & 31,6508 & 0,5576 & 27,4119 & 22,7828 \\
SSimples & 3 & 96,1872 & 125,8028 & 0,1712 & 12,1686 & 25,5664 \\
Bloco & 45 & 25,6705 & 18,1855 & 1,9102 & 33,7633 & 11,8752 \\
Erro & & & & &
\end{tabular}

${ }^{*} e^{* *}$ Significativo pelo Teste de F, a 1\% e 5\% probabilidade respectivamente.

O resultado da análise do desdobramento comportamento quadrático conforme apresentado na Figura 1. Observa-se que o ponto máximo foi registrado à $2,61 \mathrm{~kg}$ de cloreto de potássio com altura média de mudas de $45,56 \mathrm{~cm}$. Estes resultados diferem dos encontrados por SOUZA et al. (2007) que constataram um maior crescimento de mudas de tamarideiro nas doses $0,8 \mathrm{~kg} \mathrm{~m}^{-3}$ de nitrogênio com $10,0 \mathrm{~kg} \mathrm{~m}^{-3}$ de fósforo com maior altura obtida 33,72 $\mathrm{cm}$. Baseado nas considerações de SGARBI et al. (1999), ao afirmarem que a eficiência das adubações depende das doses e fontes dos adubos utilizados, da capacidade de troca catiônica e das características físicas do substrato, pode-se inferir que a interação substrato/KCl/SS no presente ensaio, foi positiva promovendo bom desenvolvimento das mudas

Para comprimento de raiz foi verificado efeito isolado do cloreto de potássio e do superfostato simples cujas respostas foram semelhantes, apresentando um comportamento quadrático com aumento seguido de queda nesta variável (Figuras
2 e 3). Este comportamento confirma a importância do fósforo no desenvolvimento radicular e corroboram com os resultados verificados por SOUZA et al. (2007) que registraram um decréscimo no tamanho das raízes de tamarindeiro à medida que se aumentaram as doses de fósforo, evidenciando que este nutriente mineral pode ser prejudicial à formação das mudas se usado em doses inadequadas.

Pela Figura 4 percebe-se que um maior número de folhas, foi resultado do efeito positivo do superfostato simples até a concentração $5 \mathrm{~kg} \mathrm{~m}^{-3}$ ocorrendo redução após este valor. Resultados similares foram obtidos por MENDONÇA et al. (2007), que também verificaram efeitos positivos da adubação fosfatada no número de folhas de sapotizeiro. De forma semelhante, SOUZA et al. (2003) em ensaio desenvolvido com gravioleira, observaram que o fertilizante superfosfato simples na dose $5 \mathrm{~kg} \mathrm{~m}^{-3}$ de substrato promoveram aumentos no número de folhas, diâmetro do caule, e matéria seca de raízes e caule. 
FERREIRA, E. A. et al. Adubação fosfatada e potássica...

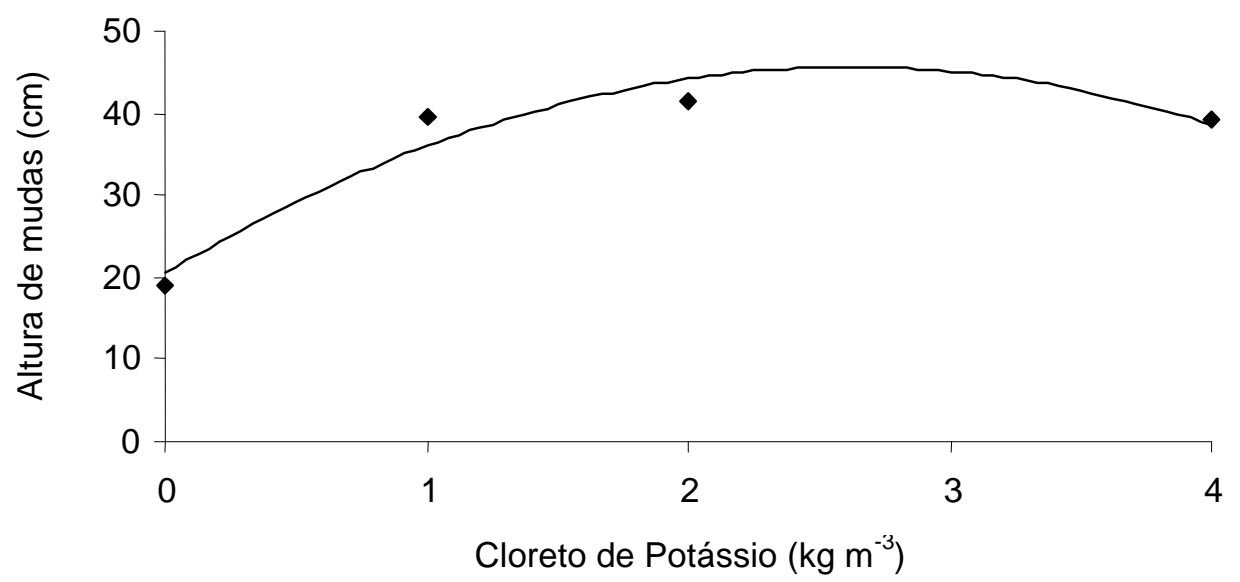

FIGURA 1 - Altura de mudas de tamarindeiro em função da adubação com cloreto de potássio. $Y=-3,65 x^{2}+$ $19,16 x+20,48 R_{2}=0,92$

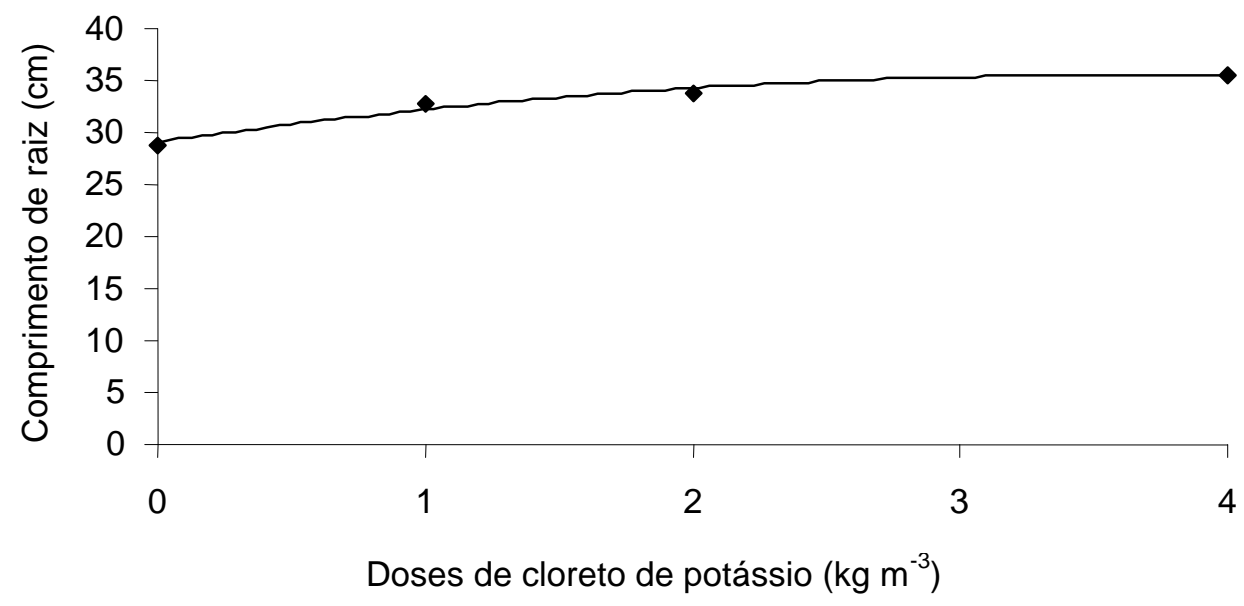

FIGURA 2 - Comprimento de raiz de tamarindeiro em função da adubação com cloreto de potássio. $Y=-0,51 x^{2}$ $+3,60 x+29,1 R_{2}=0,96$

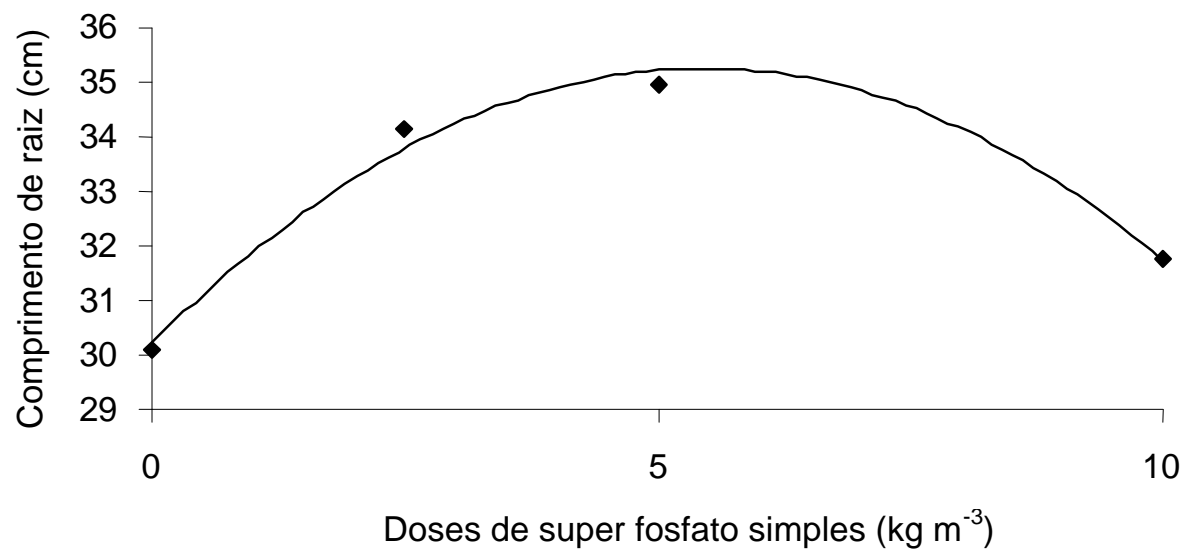

FIGURA 3 - Comprimento de raiz de tamarindeiro em função da adubação com superfosfato simples. $Y=-0,16 x^{2}+1,85 x+30,21 R_{2}=0,98$ 


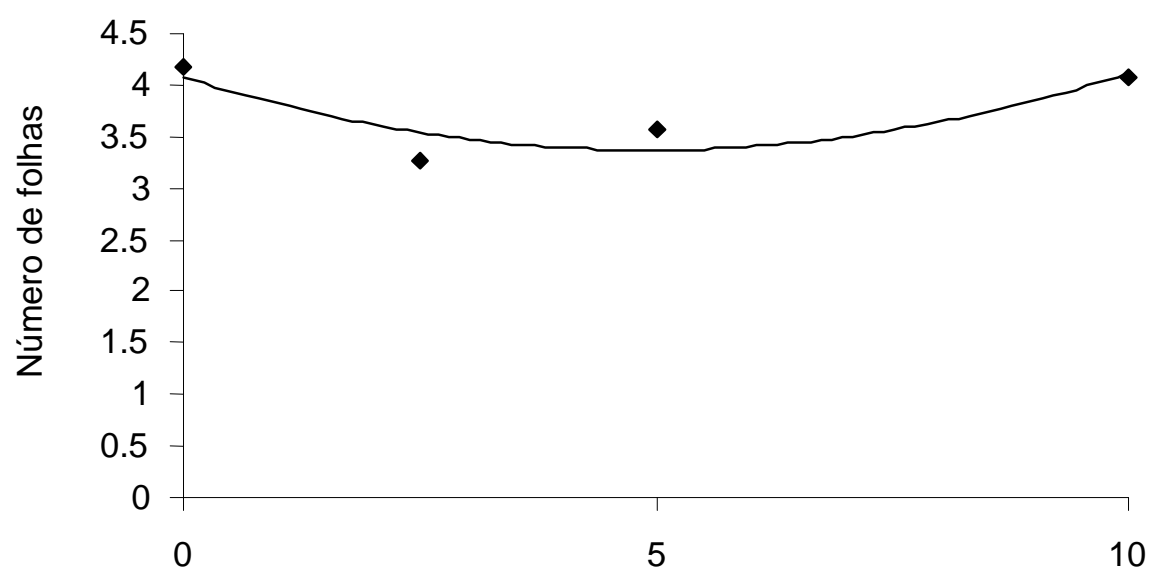

Doses de super fosfato simples $\left(\mathrm{kg} \mathrm{m}^{-3}\right)$

FIGURA 4 - Número de folhas de tamarindeiro em função da adubação com superfosfato simples. $Y=-0,0191 x^{2}+0,2892 x+3,1098 R_{2}=0,9541$

Para formação de mudas de nespereira MENDONÇA et al. (2005) recomendam incorporar ao substrato a dose de $6 \mathrm{~kg} \mathrm{~m}^{-3}$ de superfosfato simples, já para a formação de mudas de pé-franco de pitanga, ABREU et al. (2005) sugerem a incorporação de $5 \mathrm{~kg} \mathrm{~m}^{-3}$ no substrato de superfosfato simples. Assim, verifica-se que para cada fruteira, há uma necessidade ideal de nutriente requerida, principalmente no caso do fósforo.

\section{CONCLUSÕES}

$\mathrm{Na}$ formação de mudas de tamarindeiro, para o substrato empregado, recomenda-se a aplicação de $3 \mathrm{~kg} \mathrm{~m}^{-3}$ de cloreto de potássio e $5 \mathrm{~kg}$ $\mathrm{m}^{-3}$ de superfosfato simples para ganhos em para maior altura de mudas, comprimento de raiz e número de folhas.

\section{REFERÊNCIAS}

1. ALMEIDA, E. V.; NATALE, W.; PRADO R. M.; BARBOSA, J. C. Adubação nitrogenada e potássica no desenvolvimento de mudas de maracujazeiro. Ciência Rural, v. 36, n. 4, p. 1138-1142, 2006.

2. ASSOCIAÇÃO NACIONAL PARA DIFUSÃO DE ADUBOS (ANDA). Anuário Estatístico Setor de Fertilizantes, 2001. $156 \mathrm{p}$

3. CARMELLO, Q. A. de C. Nutrição e adubação de mudas hortícolas. In: MINAMI, Q. (Ed.). Produção de mudas de alta qualidade em horticultura. São Paulo: T. A. Queiroz, 1995. p. 7-27.

4. FERREIRA, D. F. Análise estatística por meio do SISVAR (Sistema para Análise de Variância) para Windows versão 4.0. In: REUNIÃO ANUAL DA REGIÃO BRASILEIRA DA SOCIEDADE INTERNACIONAL DE BIOMETRIA, 45., 2000, São Carlos. Anais... São Carlos: UFSCar, 2000. p. 255-258.

5. GOMES, F. P. Curso de estatística experimental. 14. ed. Piracicaba: USP, 2000. 477 p.

6. GURJÃO, K. C., BRUNO, R. L. A., ALMEIDA, F. A. C. Desenvolvimento de frutos e sementes de tamarindo. Revista Brasileira de Fruticultura. v. 28, n. 3, p. 351-354, 2006.

7. INSTITUTO DA POTASSA \& FOSFATO. Manual internacional de fertilidade do solo. 2. ed. Tradução e adaptação de A. S. Lopes. Piracicaba: Potafos, 1998. 177 p.

8. KLUTHCOUSKI J.; STONE, L. F. Principais fatores que interferem no crescimento radicular das culturas anuais, com ênfase no Potássio. Informações Agronômicas. n 103, p. 5-11, 2003

9. MARTINS, A. B. G.; MARCHIORI, T. T. Efeito do Armazenamento de sementes de tamarindo na porcentagem e precocidade de germinação. In: CONGRESSO BRASILEIRO DE FRUTICULTURA, 17., 2002, Belém. Anais... Belém: SBF, 2002. CD-ROM.

10. MELO, B.; ALVES, P. R. B.; LUZ, J. M. Q.; FRANZÂO, A. A.; PEIXOTO, J. R.; MARQUES, S. M. Danos no tegumento da semente do tamarindeiro no crescimento e desenvolvimento da plântula em casa de vegetação. In: CONGRESSO BRASILEIRO DE FRUTICULTURA, 18., 2004, Florianópolis. Anais... Florianópolis: SBF, 2004. CD-ROM.

11. MENDONCA, V.; ABREU, N. A. A. de, SOUZA, H. A.; TEIXEIRA, G. A.; HAFLE, O. M.; RAMOS, J. D. Diferentes ambientes e Osmocote ${ }^{\circledR}$ na produção de mudas de tamarindeiro (Tamarindus indica). Ciência Agrotecnologia, v. 32, n. 2, p. 391-397, 2008. 
FERREIRA, E. A. et al. Adubação fosfatada e potássica...

12. MENDONÇA V., CORRÊA F. L. O.; PIO R.; RUFINI J. C. M.; CARRIJO E. P.; RAMOS J. D. Superfosfato Simples e Cloreto de Potássio na formação de porta-enxerto de sapotizeiro [Manilkara zapota (L.) Von Royen]. Ciência e Agrotecnologia, v. 31, n. 1, p. 140-146, 2007.

13. NEVES O. S. C.; BENEDITO D. S; MACHADO R. V; CARVALHO J. G. Crescimento, produção de matéria seca e acúmulo de N, P, K, Ca, Mg e S na parte aérea de mudas de andiroba (Carapa guianensis Aubl.) cultivadas em solo de várzea, em função de diferentes doses de fósforo. Revista Árvore. v. 28, n. 3, p. 343-349, 2004.

14. SOUZA, C. A. S.; CORREAA, F. L. de O.; MENDONÇA, V.; CARVALHO, J. G. de. Crescimento de mudas de gravioleira (Anonna muricata L.) em substrato com superfosfato simples e vermicomposto. Revista Brasileira de Fruticultura, v. 25, n. 3, p. 453-456, 2003.

15. SOUZA, H. A.; PIO, R.; CHAGAS, E. A.; REIS, J. M. R.; RODRIGUES, H. C. A.; RAMOS, J. D.; MENDONÇA, V. Doses de nitrogênio e fósforo na formação de mudas de tamarindo. Bioscience Journal, v. 23, n. 1, p. 59-64, 2007.

16. SOUSA, H. U.; CUNHA NETO, F. R.; REZENDE E SILVA, C. R.; CARVALHO, J. G. Crescimento do sistema radicular de mudas de bananeira sob influência do substrato e superfosfato simples. Revista da Universidade de Alfenas, v. 5, p. 15-19, 1999.

17. ZUCARELI, C.; RAMOS JUNIOR, E. U.; BARREIRO, A. P.; NAKAGAWA, J.; CAVARIANI, C. Adubação fosfatada, componentes de produção, produtividade e qualidade fisiológica em sementes de feijão. Revista Brasileira de Sementes, v. 28, n. 1, p. 9-15, 2006.

Recebido em 31/01/2008

Aceito em 22/08/2008 